\title{
A HAPPY MARRIAGE OF Evolutionary AND Cross-CUltural ApProACHES
}

\author{
Gayle Brewer \\ School of Psychology, University of Liverpool, Liverpool, UK. \\ gbrewer@liverpool.ac.uk
}

A Review of the Book

\section{The Psychology of Marriage: An Evolutionary and Cross-Cultural View}

By Carol C. Weisfeld, Glenn E. Weisfeld \& Lisa M. Dillon. 2018.

Lexington Books, London. 386 pages.

ISBN 978-1-4985-4124-4 1 (Hardback, \$110.00, USD)

Few subjects capture our attention to the extent that romantic relationships do, with movies, television, and everyday gossip often focused on the formation and dissolution of such relationships. Academic literature is no exception, with a substantial body of work addressing this area. Perhaps surprisingly then, relatively few studies adopt a dyadic approach and typically obtain information from one member of the couple only. Further, this research is overwhelmingly concentrated in Western, Educated, Industrialised, Rich, and Democratic (i.e., WEIRD) countries (Henrich, Heine, \& Norenzayan, 2010), leading to an incomplete and arguably biased understanding of human relationships.

Thankfully, the authors have made a substantial contribution to this field and their work provides researchers and practitioners with a more balanced and in-depth understanding of the psychology of marriage. Their book, The Psychology of Marriage: An Evolutionary and Cross-Cultural View, provides a detailed overview of the research conducted by the authors and their research team. The scope of their research is impressive, with over 3,000 couples contributing to their projects. Hence, the book provides a valuable resource for those working in the field and readers benefit not only 
from a comprehensive review of the research literature but also from the authors' methodological approach and the practical advice afforded throughout the book.

The book is structured into four main sections. The first section focuses on fundamental and methodological issues. In particular, the authors highlight the relatively a theoretical approach taken by many disciplines which fail to fully appreciate the distinctiveness of marriage compared to other non-reproductive relationships. For those unfamiliar with the literature, there is a detailed account of the functions, evolution, and development of marriage, addressing both universal elements of marriage and important cultural variation. This is an excellent introduction to the area and clearly demonstrates the value of applying Tinbergen's four questions to the subject of marriage.

The authors then introduce the construction and properties of the Marriage and Relationship Questionnaire (MARQ) together with the value of obtaining information from both marriage partners. The authors continue with methodological and statistical issues to consider when applying psychological constructs to couples from different cultural groups and dyadic actor-partner analysis. This represents an excellent resource for those working - or considering - working in this area, particularly as the authors reference a number of reviews and guides to specific analytical techniques. It is hoped that their work will encourage others to adopt this approach especially as the book provides the Marriage and Relationship Questionnaire (MARQ) Love, Partnership, Problems with Partner, and Personal Problems Scales together with scoring instructions.

Section two contains nine chapters each exploring marriage in specific cultural contexts (e.g., Russia, Turkey, Brazil). Providing valuable context, the book includes sample information and demographics for all Marriage and Relationship Questionnaire (MARQ) datasets (i.e., American, Brazilian, British, Chinese, Gay, Lesbian, Russian, and Turkish). One of the most interesting contributions to the book provides a fascinating insight into marriage in Chinese society. The chapter demonstrates the importance of understanding those historical and societal factors which contribute to marriage and divorce trends and provides a good model for contextualizing human relationships. The section closes with detailed account of marriage in populations that have received less research attention, namely African American couples and non-heterosexual relationships. Though perhaps outside the scope of this book it would be interesting to consider the impact of being unable to enter marriage (e.g., because homosexual marriages are not permitted).

Section three addresses cross-cultural patterns in various aspects of marriage. First there is a comprehensive overview of the physical attractiveness literature. Though physical attractiveness and the recruitment of a short or long-term partner have received considerable attention within the evolutionary literature, there has been relatively little investigation of physical attractiveness in the context of marriage. Therefore, the chapter makes a welcome addition to the field. Similarly, the authors consider subjects such as religion, humour, conflict, and infidelity. Though some issues could be covered in more depth e.g., the perceptions of acts which do or do not constitute infidelity, this represents a comprehensive overview of literature in the area and will be of value to both researchers and practitioners.

In the fourth and final section, the authors provide their overall conclusions, propose a preliminary model of marriage, and discuss relevant social policy. When discussing their work, the authors state that "Many of these claims are obvious, and few are novel". 
Such models are lacking in the existing marriage literature, however, and their modesty is a greater reflection on their generous and collaborative work ethic (as International Society for Human Ethology members will be well aware) than their contribution to the field. The model provides an important framework for researchers working in the field as does their book. Overall, The Psychology of Marriage: An Evolutionary and Cross-Cultural View provides a comprehensive account of the literature and an invaluable resource for those working in the field.

\section{ABOUT THE AUTHOR}

Gayle Brewer is a Senior Lecturer for the School of Psychology at the University of Liverpool. She has published approximately 70 peer reviewed journal articles and numerous books and book chapters. Her research interests focus on the psychology of sexual and romantic relationships, with particular emphasis on the influence of personality.

\section{REFERENCES}

Henrich, J., Heine, S. J., \& Norenzayan, A. (2010). The weirdest people in the world. Behavioral and Brain Sciences, 33(2-3), 61-83. 